https://doi.org/10.48009/1_iis_2010_85-89

\title{
DO YOU WANT ME TO PUBLISH THAT NOW? A LEGAL ANALYSIS OF ONLINE PUBLISHING
}

\author{
Jason Triche, Texas Tech University. jtriche@yahoo.com \\ Sam Ramanujan University of Central Missouri. ramanujan@ucmo.edu \\ Someswar Kesh, University of Central Missouri. kesh@ucmo.edu
}

\begin{abstract}
In the pre-Internet era there was a significant time lag between the creation of a work by an author and the time a consumer read that work. The Internet has allowed authors to create and publish their work and disseminate across the world quickly. There has been an explosion of online content and publishing over the last decade. Most people believe that this trend is going to continue on a steep incline. Publishing content online in such a quick manner has drawbacks especially due to legal issues. There are several risks associated with online publishing including libel, privacy, plagiarism, copyrights, and inaccuracies. This paper highlights the various risks and provides a better understanding of Online Publishing. It also provides guidance to publishers for avoiding legal liabilities.
\end{abstract}

\section{INTRODUCTION}

Before the Internet boom, there was a significant timeframe for an author to create a piece of work to the time a consumer read that work. The Internet has allowed authors to create and publish their work and disseminate across the world quickly. There has been an explosion of online content and publishing over the last decade [3]. Most people believe that this trend is going to continue on a steep incline. Publishing content online in such a quick manner has drawbacks especially due to legal issues. There are several risks associated with online publishing including libel, privacy, plagiarism, copyrights, and inaccuracies.

This paper highlights the various risks and provides a better understanding of Online Publishing. In the remaining paper we first provide information on the process of publishing. This is followed by a section discussing the liability of various parties in different modes of publishing. Next, we discuss a few court cases

concerning liability in publishing. In particular these cases deal with libel, privacy and copyright issues. The geographic scope of liability is discussed next. Finally, in conclusion we present some recommendations that will help avoid liability for publishers.

\section{BACKGROUND AND DISCUSSION}

The art of publishing has been around for over 500 years. Publishing has been a relatively static profession over time which has established standards and protocols in place. Traditionally, "this process [publishing] is long, resulting in delayed publication of new findings. Thus, the rapid sharing of knowledge is compromised. Nonetheless, the integrity of the information is assured through this rigorous process" [2]. The traditional way of publishing allowed the publisher time and provided defined processes to check facts and provide legal reviews. This step in the publishing process minimized the risks of liability for the author and the publisher. With the shift to rapid online publishing, this step is compromised, thus resulting in exposure to legal liability. Now authors can publish their work immediately and peers can weigh in real time. With the large distribution of the Internet, there are more people that can review that work for accuracy or inaccuracies.

\section{Liability in Traditional v. Online Publishing}

Liability for wrongful or defamatory statements varies depending on the role played by the publisher. According to the law, a traditional publisher of a defamatory or false statement is just as responsible for spreading defamation as the actual author themselves. The reason behind this is that publishers exercise editorial control over content and are considered to 'know' what they have published [4]. There are other parties involved in getting the content to the public. Bookstores and libraries are part of this process but they are not considered publishers. They are 
considered "third-party institutions" according to some groups. These third party institutions usually are not held liable for the author's or publisher's work. They merely distribute the work and usually do not have any knowledge of what is in the work itself.

In the current age of online publishing, there have been many challenges to who is liable for the content. Publishing on the web is still considered publishing and must follow all the same rules as standard publishing. The challenge is to understand if the online institution is acting as a publisher or as a "thirdparty institution" like a bookstore. There are many types of online knowledge and different liabilities associated with each type.

Traditional publishing has a defined audience. The publisher controls distribution of the authors work either geographically, which could be domestic, regionally or internationally. Another way the publisher controls distribution of work is economically, which could be price of the book or distribution areas. Because the audience is defined, the exposure of which there could be a legal issue is less than in online publishing. There are several reasons why online publishing can be scrutinized more than traditional publishing including having "more eyes" on the content and also having the ability to archive it.

Since there is such a demand to quickly publish articles, it increases the legal risks for online publishers. The public expects to read about news as it happens. Because of this fast paced publishing process, online publishers do not the have time to check for accuracy compared to the traditional publishing process. The online institution has to outweigh speed for accuracy and in many cases expose themselves to legal issues.

Published material on the web is widely available and easy to access so it is easier to find inaccuracies within the content. Even if an author or publisher retracts a piece of content from the web it may still be cached. "Content might be archived by a third party - such as the Wayback Machine - and remain published long after the original publisher deleted it. This increases the risk that a plaintiff will learn of defamatory statements about them, makes it easy for them to identify precisely what was said, and potentially increases their damages because of the worldwide distribution of the content" [7].

\section{Liability in different type of web publications}

There are many types of knowledge mediums on the Web which store online content. Most of the websites on the Web can be divided into three major categories. The first category would be websites that are completely controlled by the owner. The public would not be allowed to add comments or publish content to these types of websites. This category includes majority of the Internet websites in the world. Examples of this type of websites are financial institution websites, news site, corporate websites, organization websites, etc. In a stark contrast to the first category, another type of website is one in which the community creates and shapes the website. Examples of these types of websites include travel blogs, community websites, personals websites, etc. This category has been considered the new generation of the web which creates a virtual community. The third type of category combines the first two categories in which websites are mostly controlled by the company but has a public aspect to them. An example of this would be Tivo's website, where majority of the content is controlled by Tivo but there are user forums where users can post questions and they will be answered by other public users.

"The traditional publication process does little to encourage communities with shared interests to work together in publishing their knowledge". The ability to share knowledge freely, allowing works to be annotated, discussed, reworked and republished is an advantage of online publication over traditional print publication [7]. This is one of the reasons why the community based websites have become so popular over the years. There are many advantages to this type of online content. For example, the company Palm Inc. utilizes forums on their website for consumers to search and create content. When consumers find content on their own it saves Palm time and money in their customer service department by deflecting calls. It will also benefit Palm if the consumer called and the customer service representative could point them to the website so that it may prevent a repeat call. There are other positive outcomes of community forums for Palm besides saving money on customer service 
like building brand loyalty, creative application uses, and feeling like part of a community. In some cases, consumers will write about their specific ingenuity efforts with the assumption that other people could build off of it and in return provide more creative solutions (Palm).

\section{Liability Cases in Publishing}

Traditional publishing and online publishing are bound by the same laws when it comes to liability. These laws address libel, privacy, plagiarism, and copyright issues although these are not the only problems when it comes to online publishing.

\section{Libel}

"Libel is the publication of a printing, writing, sign, picture or drawing that injures the reputation of another. It must be false in order for the plaintiff to recover damages." (MLRC). Due to the speed of online publishing and the lack of the proper publishing processes, websites are sometimes held accountable in libel suites. There have been a few cases involving online publishing in libel suites. One cased involved a company called Prodigy Services Company, an ISP, which was bought by SBC Communications in 2001. Stratton Oakmont Inc sued Prodigy for libel and they alleged "that defamatory statements had been posted by a third party on a bulletin board maintained on Prodigy" (Samson). The New York Supreme Court ruled that Prodigy acted as a publisher and not a distributor of the online bulletin board. Because of this, they were held liable because of the content on a third party bulletin board. The court believed if they were merely a distributor then they would not be held liable. This is the same analogy of a modern day bookstore which would not be held liable for the books that it sells. Once an online publisher undertakes the role of editor, he is liable for the consequences [4].

The so-called Section 230 exemption contained in the Communications Decency Act of 1996 has been used effectively by organizations to protect themselves from claims based on content from so-called third parties-whether it's a participant in a chat room or a contractor providing specific content. But the exemption starts to lose its protective power the more editorial control a company exerts over the contracted material [1]. The US Supreme Court later over turned this decision by referencing the provision in the
Communications Decency Act that excludes ISPs that are not content providers [4].

\section{Privacy}

Another legal issue with publishing is invasion of privacy or publicity. This includes disclosure of intimate and offensive material about someone, slight misrepresentations that place someone in a false light, or appropriation of someone's name or likeness (MLRC). A publisher or author can be sued for such claims. "In Stern v. Delphi Internet Services Corp., 626 NYS.2d 694 (1995), Howard Stern, a radio celebrity, sued Delphi, a provider of Internet access and related services. Delphi had created an electronic bulletin board to debate the merits of Mr. Stern's announced candidacy for New York State Governor. To advertise the bulletin board, Delphi ran advertisements in New York Magazine and in the New York Post. A portion of the ad consisted of a picture of Mr. Stern wearing leather pants that largely exposed his buttocks. Mr. Stern sued for invasion of privacy under a New York statute. Delphi claimed that use of the photograph was within the scope of the "incidental use" and "news-worthiness" exceptions to that statute. The "incidental use" exception is available to news disseminators, and the court found that the exception was apposite. The court ruled that Delphi had not acted unlawfully, but rather its services were analogous to that of a news vendor or bookstore [9]. In this case the website won the battle, but the cost of defending the litigation can be in the tens or even hundreds of thousands of dollars.

\section{Copyright Issues}

Copyright infringements are another type of legal issue that arises with online publishing. Copyright infringement is the unauthorized use of material which is covered by copyright law, in a manner that violates one of the original copyright owner's exclusive rights, such as the right to reproduce or perform the copyrighted work, or to make derivative works (MLRC). There are different ways to infringe on the copyright - direct and contributory. Direct is when the online author or publisher directly violates a copyright by using or distributing the copyrighted material. A contributory infringement is when a company or organization provides the equipment or medium used to infringe or if that company or organization has knowledge of an infringement by a third party. 
In Playboy Enterprises v. George FRENA, d/b/a Techs Warehouse BBS Systems and Consulting, and Mark Dyess, Defendants, Playboy sued Frena for copyright infringements. Frena operated a subscription computer bulletin board service, Techs Warehouse BBS ("BBS"), that distributed unauthorized copies of Plaintiff Playboy Enterprises, Inc.'s ("PEI") copyrighted photographs (Playboy). The courts ruled in favor of Playboy since Frena supplied a product with infringing copies in it and the distribution resulted in infringing displays on the bulletin board's user's computer [4]. Academia is most impacted by copyright issues. This issue can be resolved by seeking author's permission and using material for fair use as defined by law. Partial use of original work that does not lead to deterioration of the value of the original work can be considered fair use.

\section{Geographic scope of liability}

One issue that arises more in online publishing versus traditional publishing is liability outside the United States. In traditional publishing, the publishers have control of where they will distribute the content. They can weigh the legal risks of distributing to certain countries and then decide whether or not to distribute content to that country. With online publishing, the publishers do not have that privilege. Online publishers have a greater risk of being sued aboard than traditional publishers. Typically, libel laws in foreign countries are less forgiving than the U.S. first amendment rights and many times the foreign countries impose liability even when an error has occurred without fault on the part of the publisher [7]. In 2002, an Australian mining mogul named Joseph Gutnick sued Dow Jones \& Company for an article that was published on wsj.com. He alleged that Dow Jones \& Company falsely accused him of engaging in the manipulation of share prices and associating with a well-known American money launderer and tax evader [6]. Dow Jones tried to move the case to the United States where they would have greater first amendment protection on the article. The Australian courts rejected the change of venue even though the web servers were located in New Jersey citing that Gutnick's reputation was harmed in Australia not the U.S.

"In the most notable jurisdiction case decided so far, a Canadian court of appeals in September
2005 ruled that a lower court had no jurisdiction to hear a defamation claim against the Washington Post filed by former United Nations official Cheickh Bangoura. Bangoura was living in Kenya when the Post ran stories online saying that he had been investigated for sexual harassment, financial improprieties, and nepotism. But he had since moved to Canada. The appeals court not only found a negligible connection between Bangoura and his new home in Ontario but also determined he suffered no significant damage to his reputation in Canada" [1]. Finding a solution to fix international law disputes is a lengthy process and involves treaties between the different countries. Cases involving online publishing across the world will need to be settled case by case until the proper channels are in place.

\section{CONCLUDING REMARKS}

Due to the liability exposure that haunts the online publishing community, libel insurance has been created. Many insurance companies are now offering media liability insurance policies which will protect the organization against libel lawsuits. Coverage in the policies usually includes libel, slander, defamation, invasion of privacy, plagiarism, copyright infringement, or inaccurate reporting. Like all insurance policies each libel insurance policy is different when it comes to coverage, venue, settlement, recourse, and defense [10]. According to OneBeacon Insurance Company, which offers libel publishing insurance, the minimum amount of coverage is usually around $\$ 1$ million but can go as high as $\$ 50$ million for larger media organizations [7].

In conclusion, online publishing is a booming activity on the web and the trend continues to grow steadily. Companies that promote and host online publishing can be held liable just like a traditional publisher or author. Over the past few years more and more court cases are being settled and the courts are trying to define who is responsible for the libel claims. A general rule from the courts is if a company is acting like a publisher or editor then they are liable. If the company is merely a "third-party institution" then they are not responsible for the content on their website much like a book store or library. In this era of lawsuits it would be wise for 
companies that participate in online publishing to look into the cost benefit analysis of libel insurance. Many online publishers are small companies and one claim whether they win or lose could wipe them out.

\section{References}

[1]. Halloran, Liz. "Online publishing and libel law." US News and World Report. March 4, 2006. Online. http://www.usnews.com/usnews/news/a $\underline{\text { rticles/060404/4mediatakes_2.htm }}$

[2]. Henry, Geneva. "On-line Publishing in the $21^{\text {st }}$ Century." D-Lib Magazine. October 2003. http://www.dlib.org/dlib/october03/henr y/10henry.html

[3]. Goodman, Mark. "Legal Issues for Publishing”. NSPA Guidebook. 2010. http://studentpress.journ.umn.edu/nspa/pdf/whee 1_legalissuesonline.pdf.

[4]. "Liability for the Wrongful Acts of Publishers.” December 2004. Online.

[10]. Zhang, Wende. "Digital Library Intellectual Property Right Evaluation and
http://www.utsystem.edu/OGC/Intellect ualproperty/publia.htm

[5]. Palm Website. http://forums.palm.com

[6]. Playboy Enterprises, Inc., v. George Frena, $\mathrm{d} / \mathrm{b} / \mathrm{a}$ Techs Warehouse BBS Systems and Consulting, and Mark Dyess,

Defendants. 1993 839 F.Supp. 1552 No. 93489-Civ-J-20

[7]. Rothberg, Michael. "Online Publishing Risks Create Need for Libel Insurance." Online Journalism Review. Feburary 2004. http://www.ojr.org/ojr/law/1077150111.php

[8]. Samson, Martin. "Stratton Oakmont, Inc. et al. v. Prodigy Services Company, et al." Online. http://www.internetlibrary.com/cases/lib_case80. $\underline{\mathrm{cfm}}$

[9]. Uhler, Scott, and Phillipe Weiss. "Liability Issues and the Internet Part 3". Illinois Periodicals Online. http://c60jdh1.lib.niu.edu/ipo/1996/i19604207.ht $\mathrm{ml}$.

Method." The Electronic Library 25, no. 3

(2007): 267-273. 